\title{
Erratum to: Transformed eddy-PV flux and positive synoptic eddy feedback onto low-frequency flow
}

\author{
Hong-Li Ren · Fei-Fei Jin · Jong-Seong Kug • \\ Li Gao
}

Published online: 1 July 2011

(C) Springer-Verlag 2011

\section{Erratum to: Clim Dyn (2011) 36:2357-2370 \\ DOI 10.1007/s00382-010-0913-0}

In the original publication incorrect information was published in the Acknowledgment section and the correct statement is given below:

Acknowledgments This work is jointly supported by National Science foundation (NSF) grants ATM 0938027 and ATM 1034439, and NSF of China (NSFC) grants
(40705021, 40805028), 973 Program (2010CB950404), the National Science and Technology Support Program of China (2007BAC29B03), and the Meteorological Special Project (GYHY200806005, GYHY200906015). J.-S. Kug is supported by the Korea Meteorological Administration Research and Development Program under Grant CATER_2010-2209. The authors especially express their thanks to J.-X. Zhao and A. F. Z. Levine for their careful proof-reading and revising.

The online version of the original article can be found under doi:10.1007/s00382-010-0913-0.

H.-L. Ren $(\bowtie) \cdot$ L. Gao

School of Ocean and Earth Sciences and Technology,

University of Hawaii, Honolulu, HI 96822, USA

e-mail: honglir@hawaii.edu

H.-L. Ren

Laboratory for Climate Studies, National Climate Center,

China Meteorological Administration, Beijing 100081, China

J.-S. Kug

Korea Ocean Research and Development Institute,

Ansan 425-600, Korea

L. Gao

Numerical Prediction Center, National Meteorological Center,

China Meteorological Administration, Beijing 100081, China 